\title{
Potencial Forrageiro de Novos Clones de Capim-Elefante
}

\section{Milton de Andrade Botrel1, ${ }^{1}$, Antônio Vander Pereira1, Vicente de Paula Freitas ${ }^{3}$, Deise Ferreira Xavier ${ }^{1}$}

\begin{abstract}
RESUMO - O objetivo deste trabalho foi avaliar o comportamento de novos clones selecionados de capim-elefante. O experimento foi realizado na Embrapa Gado de Leite, em Coronel Pacheco - MG, por um período de dois anos. Foi avaliado o potencial forrageiro de 20 clones de capim-elefante, obtidos pelo programa de melhoramento, e mais duas cultivares tradicionais (Cameroon e Taiwan A146) usadas como testemunhas. O delineamento experimental foi o de blocos ao acaso com quatro repetições. As adubações para estabelecimento e manutenção foram realizadas de acordo com a análise do solo, visando suprir as exigências nutricionais do capim-elefante. Observaram-se diferenças significativas entre os clones, quanto ao potencial para produção de forragem, à relação folha/colmo e ao perfilhamento aéreo e basal. A maioria dos clones avaliados apresentou maior produção de matéria seca que as cultivares tradicionais, Cameroon e Taiwan A-146, durante o período seco e chuvoso. Não houve diferença significativa no teor de proteína bruta da matéria seca das cultivares controles (Cameroon e Taiwan A-146) e dos clones avaliados, em ambas as estações (águas e seca). O clone F 27-01, lançado pela Embrapa Gado de Leite com o nome de cultivar Pioneiro, destacou-se para quase todas as características agronômicas estudadas.
\end{abstract}

Palavras-chave: adaptação, cv. Pioneiro, nova variedade, Pennisetum purpureum Schum., produtividade, qualidade

\section{Forage Potential of News Clones of Elephantgrass}

\begin{abstract}
The objective of this experiment was to evaluate the forage potential of new selected clones of elephantgrass. The evaluation was conducted at the Dairy Cattle Research Centre - EMBRAPA, Coronel Pacheco, Minas Gerais, for two consecutive years. Twenty selected clones obtained by the elephantgrass breeding program were evaluated, and two traditional cultivars Cameroon and Taiwan A -146 were used as control. The experimental procedure was a randomized block design with four replicates. The fertilization for both establishment and maintenance was applied according to the soil chemical analysis and elephant grass nutritional requirements. Significant differences among the clones were observed regarding to forage production potential, leaf:stem ratio, and aerial and basal tillering. The majority of the evaluated new clones were superior to the traditional cultivars Cameroon and Taiwan A-146 with relation to dry matter production during the dry and rainy periods. Crude protein content in the forage did not differ among the new clones and the control cultivars (Cameroon and Taiwan A-146), during both dry and rainy seasons. The clone F 27-01, released as elephant grass cultivar Pioneiro, was superior for the most evaluated agronomic traits.
\end{abstract}

Key Words: adaptation, cv. Pioneiro, new variety, Pennisetum purpureum Schum., productivity, quality

\section{Introdução}

Na maioria das propriedades de exploração leiteira, tem sido crescente o uso de pastagens como principal fonte de volumoso para vacas em lactação. Segundo ASSIS (1982), esse fato se deve não somente à grande extensão de terras disponíveis nas regiões tropicais para a produção animal, como também ao elevado custo dos alimentos processados e concentrados.

As gramíneas forrageiras podem fornecer de 60 a $70 \%$ da dieta volumosa para vacas em lactação (ETGEN et al., 1987). A contribuição desses volumosos na alimentação do rebanho pode variar em função do grau de intensificação da exploração leiteira e do grau de especialização ou exigência nutricional do rebanho, podendo chegar a $100 \%$ em sistemas menos intensivos, nos quais se utilizam animais de menor potencial genético para produção de leite.

Entre as gramíneas tropicais, o capim-elefante (Pennisetum purpureum Shum.) destaca-se pela alta produtividade e qualidade da forragem. Pode ser usado sob diversas formas (capineira, pastejo, silagem etc.), sendo uma das forrageiras que mais contribui para a produção de leite, no Brasil Central, como capineira.

O elevado potencial do capim-elefante para produção de leite, quando utilizado sob a forma de

\footnotetext{
1 Pesquisador da Embrapa Gado de Leite, Centro Nacional de Pesquisa de Gado de Leite. Rua Eugênio do Nascimento, 610, CEP 36038-330, Juiz de Fora, MG. Bolsista do CNPq. E. mail: mbotrel@cnpgl.embrapa.br; avander@cnpgl.embrapa.br; dfxavier@cnpgl.embrapa.br

2 Bolsista do CNPq

3 Técnico Especializado da Embrapa Gado de Leite.
} 
pastejo rotativo, foi demonstrado por MATTOS (1997). Assim, na região da Zona da Mata de Minas Gerais, têm-se conseguido, em pastagens de capimelefante, manejada em sistema rotativo, produções de leite acima de $15.000 \mathrm{~kg} / \mathrm{ha} / \mathrm{ano}$, com taxa de lotação de 4 a 6 vacas/ha (DEREZ et al., 1994). Entretanto, PEREIRA (1993) afirma que a utilização do capim-elefante para pastejo direto ainda depende do desenvolvimento de novas cultivares adaptadas a esse sistema. Segundo CORSI (1993), a produção de matéria seca do capim-elefante, em sistemas de pastejo, depende basicamente do perfilhamento aéreo, que, por sua vez, está diretamente relacionado com o número de perfilhos basais.

Durante o período das chuvas, e quando manejado intensivamente, o capim-elefante pode atingir produções diárias superiores a $200 \mathrm{~kg} / \mathrm{ha}$ de matéria seca, com teor de proteína bruta em torno de $15 \%$ (GOMIDE, 1994). Por outro lado, a estacionalidade da produção de forragem durante o período seco do ano é bastante acentuada, constituindo uma das principais limitações dessa espécie forrageira. Assim, para a maioria das cultivares existentes, somente 10-15\% da produção anual de forragem são produzidos durante o período da seca (BOTREL e ALVIM, 1992).

O presente trabalho teve como objetivo avaliar o comportamento forrageiro de novos clones de capimelefante, visando identificar os mais promissores em termos de distribuição estacional da produção e da qualidade da forragem.

\section{Material e Métodos}

O experimento foi conduzido no campo experimental da Embrapa Gado de Leite, localizado em Coronel Pacheco, Zona da Mata de Minas Gerais, no período de abril de 1994 a setembro de 1996. O clima da região é do tipo Cwa, mesotérmico, apresentando verão quente e chuvoso e inverno frio e seco. A precipitação média anual situa-se ao redor de 1500 $\mathrm{mm}$, distribuídos irregularmente, e somente $13 \%$ desse total ocorre durante os meses de maio a setembro, considerado como o período da seca. A temperatura média é de $18^{\circ} \mathrm{C}$ nos meses mais frios e $22^{\circ} \mathrm{C}$ durante o período de verão.

O solo onde foi instalado o experimento é o predominante na região, classificado como Latossolo Vermelho-Amarelo, apresentando as seguintes características químicas: $\mathrm{pH}$ em água $=5,14 ; \mathrm{Al}^{+++}=$ $0,1 \mathrm{cmol}_{\mathrm{c}} / \mathrm{dm}^{3} ; \mathrm{Ca}^{++}+\mathrm{Mg}^{++}=1,68 \mathrm{cmol}_{\mathrm{c}} / \mathrm{dm}^{3}$; $\mathrm{P}=2,46 \mathrm{mg} / \mathrm{dm}^{3}$; e $\mathrm{K}=0,19 \mathrm{mg} / \mathrm{dm}^{3}$.
Foram avaliados 20 novos clones de capim-elefante obtidos pelo programa de melhoramento genético de forrageiras da Embrapa Gado de Leite. Para fins de comparação dos resultados foram utilizadas, como padrão, as cultivares de capim-elefante Taiwan A-146 e Cameroon.

O delineamento experimental adotado foi o de blocos casualisados, com quatro repetições, sendo utilizadas parcelas com quatro linhas de $4,0 \mathrm{~m}$ de comprimento, espaçadas de $60 \mathrm{~cm}$ entre si (parcelas de $4,0 \times 1,8 \mathrm{~m}$ ).

A calagem foi realizada dois meses antes do plantio e consistiu da aplicação de 2 t/ha de calcário dolomítico. A adubação para estabelecimento foi feita nos sulcos de plantio com $100 \mathrm{~kg} / \mathrm{ha}$ de $\mathrm{P}_{2} \mathrm{O}_{5}$ (superfosfato simples) e $50 \mathrm{~kg} / \mathrm{ha}$ de $\mathrm{K}_{2} \mathrm{O}$ (cloreto de potássio). Aproximadamente dois meses após o plantio, foram aplicados em cobertura, em toda a área experimental, $50 \mathrm{~kg} / \mathrm{ha}$ de $\mathrm{N}$ na forma de sulfato de amônio. A adubação de manutenção foi realizada anualmente na dosagem equivalente a 150 e $100 \mathrm{~kg} / \mathrm{ha}$ de $\mathrm{N}$ (sulfato de amônio) e $\mathrm{K}_{2} \mathrm{O}$ (cloreto de potássio), respectivamente, parcelada em três aplicações durante o período das chuvas.

Cada tratamento foi avaliado durante um período de aproximadamente dois anos, quanto à produção e distribuição estacional da forragem, ao teor de proteína bruta (BREMNER, 1965), à relação folha/colmo e ao número de perfilhos aéreos e basais. A estimativa da produção de forragem foi feita nas duas fileiras centrais de cada parcela, em uma área útil de $3,6 \mathrm{~m}^{2}(3,0 \times 1,20 \mathrm{~m})$, e os cortes foram realizados a $50 \mathrm{~cm}$ do solo e sempre que a maioria dos tratamentos (clones) atingissem cerca de 1,80 m de altura, no período das chuvas, e 1,50 m no período seco. Esse manejo permitiu obter, em média, quatro cortes durante a estação das chuvas e dois na da seca, que foram realizados nas seguintes datas: 10/11/94, 11/01/95, $30 / 03 / 95,01 / 06 / 95,22 / 08 / 95,24 / 10 / 95,12 / 12 / 95$, 13/02/96, 09/04/96, 12/06/96, 16/09/96 e 29/10/96. Na amostra colhida para a estimativa da produção de forragem, nos cortes realizados durante o período das águas, retirou-se uma subamostra por parcela, para determinação do teor de proteína bruta. Na estação da seca, a amostragem, também realizada em cada corte, foi feita simulando o pastejo, por intermédio da colheita manual da forragem (DAYRELL e NOVAES, 1992). A avaliação do perfilhamento foi realizada nos cortes efetuados durante o período da seca, por meio da contagem do número de perfilhos resultantes do desenvolvimento das gemas axilares (perfilhos aére- 
336 Rev. bras. zootec.

os) e dos originários das gemas basais (perfilhos basais) contidos na área útil de cada parcela. Para a determinação da relação folha/colmo, foram retirados aleatoriamente, por época dos cortes, 20 perfilhos da área útil de cada parcela e separadas, manualmente, as folhas dos colmos, para posterior determinação do peso seco de cada componente.

Os resultados foram submetidos à análise de variância e optou-se, para a comparação das médias, pelo teste de agrupamentos de Scott-Knott, devido à sua maior sensibilidade na comparação de número elevado de médias.

\section{Resultados e Discussão}

Produção de matéria seca (MS)

Os dados contidos na Tabela 1 mostram que houve diferenças significativas $(\mathrm{P}<0,05)$ entre os tratamentos, quanto à produção de MS na época da seca, das chuvas e anual.

No período seco, a produção média de MS foi de $5782 \mathrm{~kg} / \mathrm{ha}$, variando de 7932 (clone F 02-05) a 3716 $\mathrm{kg} / \mathrm{ha}$ de MS (clone F 35-04). Os clones que apresentaram maior produção de MS nesta época foram: $\mathrm{F}$ 02-05, F 27-01, F 27-05, Cameroon, F 11-02, F 02-04,

Tabela 1 - Produção (kg/ha) e distribuição estacional de matéria seca (MS) de cultivares e clones selecionados de capim-elefante

Table 1 - Yield ( $\mathrm{kg} / \mathrm{ha}$ ) and seasonal dry matter distribution of cultivars and selected clones of elephant grass

\begin{tabular}{|c|c|c|c|c|}
\hline \multirow{2}{*}{$\begin{array}{l}\text { Tratamento } \\
\text { Treatment }\end{array}$} & \multicolumn{3}{|c|}{$\begin{array}{l}\text { Produção de matéria seca }(\mathrm{kg} / \mathrm{ha}) \\
\text { Dry matter production }(\mathrm{kg} / \mathrm{ha})\end{array}$} & \multirow[b]{2}{*}{$\begin{array}{c}\mathrm{A} / \mathrm{B} \times 100 \\
(\%)\end{array}$} \\
\hline & $\begin{array}{l}\text { Período seco } \\
\text { Dry period } \\
\text { (A) }\end{array}$ & $\begin{array}{l}\text { Período da água } \\
\text { Rainy period }\end{array}$ & $\begin{array}{l}\text { Anual } \\
\text { Annual } \\
\text { (B) }\end{array}$ & \\
\hline 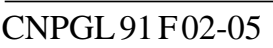 & $7,932^{A^{*}}$ & $31,048^{\mathrm{A}}$ & $38,980^{\mathrm{A}}$ & 20 \\
\hline CNPGL 91 F 27-01 & $7,332^{\mathrm{A}}$ & $35,863^{\mathrm{A}}$ & $43,195^{\mathrm{A}}$ & 17 \\
\hline CNPGL91 F 27-05 & $7,311^{\mathrm{A}}$ & $33,976^{\mathrm{A}}$ & $41,287^{\mathrm{A}}$ & 18 \\
\hline CAMEROON & $6,963^{A}$ & $24,259^{\mathrm{B}}$ & $31,222^{\mathrm{B}}$ & 22 \\
\hline CNPGL 91 F 11-02 & $6,887^{\mathrm{A}}$ & $23,991^{\mathrm{B}}$ & $30,878^{\mathrm{B}}$ & $\overline{22}$ \\
\hline CNPGL 91 F 02-04 & $6,681^{A}$ & $24,329^{\mathrm{B}}$ & $31,010^{\mathrm{B}}$ & 21 \\
\hline CNPGL 91 F06-03 & $6,615^{\mathrm{A}}$ & $30,269^{\mathrm{A}}$ & $36,885^{\mathrm{A}}$ & 17 \\
\hline CNPGL 91 F 34-05 & $6,605^{\mathrm{A}}$ & $26,319^{\mathrm{B}}$ & $32,924^{\mathrm{B}}$ & 20 \\
\hline CNPGL 91 F 19-05 & $6,551^{\mathrm{A}}$ & $20,710^{\mathrm{B}}$ & $27,261^{\mathrm{B}}$ & 24 \\
\hline CNPGL 91 F04-01 & $6,380^{\mathrm{A}}$ & $25,523^{\mathrm{B}}$ & $31,903^{\mathrm{B}}$ & 20 \\
\hline CNPGL 91 F 19-01 & $6,089^{\mathrm{A}}$ & $24,965^{\mathrm{B}}$ & $31,054^{\mathrm{B}}$ & 20 \\
\hline TAIWAN A-146 & $5,992^{\mathrm{A}}$ & $19,918^{\mathrm{B}}$ & $25,910^{\mathrm{B}}$ & 23 \\
\hline CNPGL 91 F01-02 & $5,899^{\mathrm{A}}$ & $24,178^{\mathrm{B}}$ & $30,077^{\mathrm{B}}$ & 20 \\
\hline CNPGL 91 F 32-01 & $5,238^{\mathrm{A}}$ & $25,438^{\mathrm{B}}$ & $30,676^{\mathrm{B}}$ & 17 \\
\hline CNPGL91 F 28-01 & $5,232^{\mathrm{B}}$ & $25,862^{\mathrm{B}}$ & $31,094^{\mathrm{B}}$ & 17 \\
\hline CNPGL $91 \mathrm{~F} 17-05$ & $5,059^{\mathrm{B}}$ & $23,012^{\mathrm{B}}$ & $28,071^{\mathrm{B}}$ & 18 \\
\hline CNPGL $91 \mathrm{~F} 10-02$ & $4,964^{\mathrm{B}}$ & $22,180^{\mathrm{B}}$ & $27,144^{\mathrm{B}}$ & 18 \\
\hline CNPGL 91 F 13-02 & $4,150^{\mathrm{B}}$ & $22,636^{\mathrm{B}}$ & $26,786^{\mathrm{B}}$ & 15 \\
\hline CNPGL 91 F 25-03 & $3,987^{\mathrm{B}}$ & $21,15^{\mathrm{B}}$ & $25,145^{\mathrm{B}}$ & 16 \\
\hline CNPGL 91 F 33-01 & $3,850^{\mathrm{B}}$ & $30,244^{\mathrm{A}}$ & $34,094^{\mathrm{A}}$ & 11 \\
\hline CNPGL $91 \mathrm{~F} 10-05$ & $3,773^{\mathrm{B}}$ & $16,403^{\mathrm{B}}$ & $20,176^{\mathrm{B}}$ & 18 \\
\hline CNPGL 91 F 35-04 & $3,716^{\mathrm{B}}$ & $17,474^{\mathrm{B}}$ & $21,190^{\mathrm{B}}$ & 17 \\
\hline Média & 5,782 & 24,989 & 30,771 & 18 \\
\hline Mean & & & & \\
\hline
\end{tabular}

* Médias seguidas pela mesma letra na coluna não diferem $(P>0,05)$ pelo teste Scott-Knott.

* Means followed by identical letters in the same column did not differ $(P>.05)$ by Scott-Knott test. 
F 06-03, F 34-05, F 19-05, F 04-01, F 19-01, Taiwan A-146 e F 01-02. As produções de MS obtidas neste trabalho, durante a época da seca, foram superiores às alcançadas com outras gramíneas tropicais, por PEDREIRA e MATTOS (1981), e semelhantes às produções conseguidas por BOTREL et al. (1994), com diferentes cultivares de capim-elefante avaliados sob condições de pastejo na região da Zona da Mata de Minas Gerais.

No período das chuvas, os clones mais produtivos foram: F 27-01 (35.863 kg/ha de MS), F $27-05$ (33.976 kg/ha de MS), F 02-05 (31.048 kg/ha de MS), F 06-03 (30.269 kg/ha de MS) e F 33-01 (30.244 kg/ha de MS), enquanto a produção de MS das testemunhas foi 24.259 e $19.918 \mathrm{~kg} / \mathrm{ha}$, respectivamente, para as cultivares Cameroon e Taiwan A-146 (Tabela 1). Considerando os clones com maior produtividade no período chuvoso, apenas o clone F 33-01 não apresentou bom comportamento na estação seca. Isto demonstra que este clone concentra a produção de MS, principalmente no período das chuvas, não constituindo, portanto, boa opção para produção de leite a pasto, pois esta alternativa necessita de cultivares que apresentem oferta mais constante de forragem ao longo do ano. Os valores extremos de produção de MS observados na época das chuvas foram $35.863 \mathrm{~kg}$ (clone F 27-01) e $16.403 \mathrm{~kg}$ (clone F 10-05).

A produtividade média anual de MS obtida, considerando todos os tratamentos, foi $30.771 \mathrm{~kg} / \mathrm{ha}$ (Tabela 1). Os clones com maior produtividade anual foram os mesmos que se destacaram no período das chuvas, sendo esta época do ano a responsável pela discriminação dos clones mais produtivos. A produção do período das chuvas foi, em média, $82 \%$ superior à produção da época seca. Essa marcante estacionalidade na produção de forragem do capimelefante foi também observada por ZUNIGA et al. (1967), CARVALHO (1985) e BOTREL et al. (1994). A concentração da produção no período das chuvas é considerada importante problema na utilização do capim-elefante, em razão das flutuações entre a oferta de forragem e a demanda de alimentos pelo rebanho, a qual permanece constante durante o ano.

Os clones com produção de matéria seca mais equilibrada durante o ano foram: F 19-05 (24\% na seca), Taiwan A-146 (23\%), F 11-02 (22\%) e Cameroon $(22 \%)$. Entretanto, nenhum deles se situou entre os que apresentaram maior rendimento anual de forragem. Isto significa que o progresso no melhoramento do capim-elefante deve ser direcionado no sentido de aumentar a produção de forragem no período da seca. No sistema de pastejo rotativo, o uso de cultivares de capim-elefante de alto rendimento forrageiro, aliado à melhor distribuição da produção de matéria seca, durante todo o ano, constitui uma forma de manter a produtividade de leite e, com isso, diminuir a necessidade de forragens conservadas e de concentrados no período da seca.

Teor de proteína bruta $(P B)$, relação folha:colmo (F/C) e perfilhamento aéreo e basal

Observou-se diferença significativa $(\mathrm{P}<0,05)$ entre os tratamentos, quanto à relação folha/colmo $(\mathrm{F} / \mathrm{C})$, tanto na estação das chuvas, como no período seco do ano (Tabela 2). A relação F/C no período chuvoso foi superior à observada no período da seca para todos os tratamentos, confirmando a expectativa de maior crescimento de folhas que de colmos nessa época do ano.

Essa relação, no período da seca, variou de 2,10 (clone F 10-02) a 0,62 (clone F 27-05). As testemunhas, cultivares Cameroon e Taiwan-146, situaram-se, respectivamente, no grupo dos tratamentos que apresentaram maior e menor proporção de folhas no período da seca, respectivamente, confirmando os resultados encontrados por SANTANA et al. (1989), BOTREL e ALVIM (1992), BOTREL et al. (1994) e POLI et al. (1994). O florescimento do capim-elefante é concentrado no período da seca, sendo esta fase caracterizada pelo alongamento das células dos entrenós recémformados, resultando em menor relação $\mathrm{F} / \mathrm{C}$ (ANDRADE e GOMIDE, 1971), como neste trabalho.

$\mathrm{Na}$ estação das chuvas, a relação $\mathrm{F} / \mathrm{C}$ variou de 3,00 a 1,05, respectivamente, nos clones F 10-02 e F 27-05. Considerando todos os tratamentos avaliados, o valor médio dessa relação foi de 1,42 e 2,14, respectivamente, no período da seca e das chuvas. A relação F/C é fator importante na previsão do valor nutritivo de uma cultivar, pois indica a proporção de caules que está presente na forragem total, os quais são de menor valor nutritivo, quando comparados com as folhas. Assim, a alta proporção de folhas em relação aos colmos constitui uma característica desejável em uma planta forrageira, por estar diretamente associada com a qualidade e o consumo, principalmente em espécies que apresentam colmos mais grossos como o capim-elefante (LAREDO e MINSON, 1973). No presente trabalho, 36 e $86 \%$ dos clones avaliados apresentaram relação F/C superiores aos das cultivares Cameroon e Taiwan A-146, respectivamente.

Ao se compararem as Tabelas 1 e 2, constata-se que, de maneira geral, as baixas relações $\mathrm{F} / \mathrm{C}$ foram 
338 Rev. bras. zootec.

Tabela 2 - Relação folha/colmo, teor de proteína bruta e perfilhamento aéreo e basal de cultivares e clones selecionados de capim-elefante

Table 2 - Leaf:stem ratio, crude protein content, and aerial and basal tillering of cultivars and selected clones of elephant grass

\begin{tabular}{|c|c|c|c|c|c|c|}
\hline \multirow{4}{*}{$\begin{array}{l}\text { Tratamento } \\
\text { Treatment }\end{array}$} & \multicolumn{2}{|c|}{$\begin{array}{c}\text { Relação Folha/Colmo } \\
\text { Leaf:stem ratio }\end{array}$} & \multicolumn{2}{|c|}{$\begin{array}{c}\text { Proteína bruta }(\%) \\
\text { Crude protein }\end{array}$} & \multicolumn{2}{|c|}{$\begin{array}{c}\text { Perfilho } / \mathrm{m}^{2} \\
\text { Tiller } / \mathrm{m}^{2}\end{array}$} \\
\hline & \multirow{2}{*}{\multicolumn{2}{|c|}{$\begin{array}{l}\text { Período } \\
\text { Period }\end{array}$}} & \multirow{2}{*}{\multicolumn{2}{|c|}{$\begin{array}{c}\text { Período } \\
\text { Period }\end{array}$}} & \multirow[b]{3}{*}{$\begin{array}{l}\text { Aéreo } \\
\text { Aerial }\end{array}$} & \multirow[b]{3}{*}{$\begin{array}{l}\text { Basa } \\
\text { Basal }\end{array}$} \\
\hline & & & & & & \\
\hline & $\begin{array}{l}\text { Seca } \\
\text { Dry }\end{array}$ & $\begin{array}{l}\text { Chuva } \\
\text { Rainy }\end{array}$ & $\begin{array}{l}\text { Seca }^{1} \\
\text { Dry }\end{array}$ & $\begin{array}{c}\text { Chuva }^{2} \\
\text { Rainy }\end{array}$ & & \\
\hline$\overline{\text { CNPGL 91 F 10-02 }}$ & $2,10^{\mathrm{A}}$ & $3,00^{\mathrm{A}}$ & $11,82^{\mathrm{A}}$ & $8,39^{\mathrm{A}}$ & $133^{\mathrm{B}}$ & $32^{\mathrm{B}}$ \\
\hline CNPGL $91 \mathrm{~F} 10-05$ & $2,01^{\mathrm{A}}$ & $2,46^{\mathrm{A}}$ & $10,18^{\mathrm{A}}$ & $9,32^{\mathrm{A}}$ & $115^{\mathrm{B}}$ & $18^{\mathrm{B}}$ \\
\hline CNPGL 91 F 02-05 & $1,86^{\mathrm{A}}$ & $2,19^{\mathrm{A}}$ & $9,23^{\mathrm{A}}$ & $7,52^{\mathrm{A}}$ & $146^{\mathrm{B}}$ & $27^{\mathrm{B}}$ \\
\hline CNPGL 91 F 19-05 & $1,83^{\mathrm{A}}$ & $2,68^{\mathrm{A}}$ & $11,10^{\mathrm{A}}$ & $7,07^{\mathrm{A}}$ & $192^{\mathrm{A}}$ & $34^{\mathrm{B}}$ \\
\hline CNPGL $91 \mathrm{~F} 19-10$ & $1,74^{\mathrm{A}}$ & $2,28^{\mathrm{A}}$ & $11,65^{\mathrm{A}}$ & $7,90^{\mathrm{A}}$ & $93^{\mathrm{B}}$ & $31^{\mathrm{B}}$ \\
\hline CNPGL 91 F 17-05 & $1,70^{\mathrm{A}}$ & $2,49^{\mathrm{A}}$ & $10,17^{\mathrm{A}}$ & $6,76^{\mathrm{A}}$ & $169^{\mathrm{A}}$ & $33^{\mathrm{B}}$ \\
\hline CNPGL 91 F 02-04 & $1,62^{\mathrm{A}}$ & $2,30^{\mathrm{A}}$ & $10,05^{\mathrm{A}}$ & $7,25^{\mathrm{A}}$ & $101^{\mathrm{B}}$ & $28^{\mathrm{B}}$ \\
\hline CNPGL 91 F 32-01 & $1,62^{\mathrm{A}}$ & $2,53^{\mathrm{A}}$ & $11,01^{\mathrm{A}}$ & $7,49^{\mathrm{A}}$ & $185^{\mathrm{A}}$ & $41^{\mathrm{B}}$ \\
\hline CAMEROON & $1,61^{\mathrm{A}}$ & $2,24^{\mathrm{A}}$ & $10,99^{\mathrm{A}}$ & $6,71^{\mathrm{A}}$ & $107^{\mathrm{B}}$ & $32^{\mathrm{B}}$ \\
\hline CNPGL 91 F 35-04 & $1,60^{\mathrm{A}}$ & $2,43^{\mathrm{A}}$ & $9,95^{\mathrm{A}}$ & $6,80^{\mathrm{A}}$ & $97^{\mathrm{B}}$ & $27^{\mathrm{B}}$ \\
\hline CNPGL $91 \mathrm{~F} 11-02$ & $1,59^{\mathrm{A}}$ & $2,65^{\mathrm{A}}$ & $11,82^{\mathrm{A}}$ & $7,83^{\mathrm{A}}$ & $173^{\mathrm{A}}$ & $38^{\mathrm{A}}$ \\
\hline CNPGL 91 F 25-03 & $1,55^{\mathrm{A}}$ & $1,78^{\mathrm{B}}$ & $11,31^{\mathrm{A}}$ & $7,10^{\mathrm{A}}$ & $96^{\mathrm{B}}$ & $20^{\mathrm{B}}$ \\
\hline CNPGL 91 F 06-03 & $1,53^{\mathrm{A}}$ & $2,34^{\mathrm{A}}$ & $10,30^{\mathrm{A}}$ & $6,81^{\mathrm{A}}$ & $132^{\mathrm{B}}$ & $31^{\mathrm{B}}$ \\
\hline CNPGL 91 F 01-02 & $1,48^{\mathrm{A}}$ & 2,40 & $11,93^{\mathrm{A}}$ & $7,62^{\mathrm{A}}$ & $153^{\mathrm{B}}$ & $43^{\mathrm{A}}$ \\
\hline CNPGL 91 F 28-01 & $1,41^{\mathrm{A}}$ & $1,91^{\mathrm{B}}$ & $11,22^{\mathrm{A}}$ & $5,74^{\mathrm{A}}$ & $225^{\mathrm{A}}$ & $50^{\mathrm{A}}$ \\
\hline CNPGL $91 \mathrm{~F} 13-02$ & $1,28^{\mathrm{B}}$ & $1,70^{\mathrm{B}}$ & $11,88^{\mathrm{A}}$ & $7,82^{\mathrm{A}}$ & $145^{\mathrm{B}}$ & $35^{\mathrm{B}}$ \\
\hline CNPGL 91 F 33-01 & $1,27^{\mathrm{B}}$ & $1,70^{\mathrm{B}}$ & $11,18^{\mathrm{A}}$ & $6,83^{\mathrm{A}}$ & $233^{\mathrm{A}}$ & $48^{\mathrm{A}}$ \\
\hline CNPGL 91 F 04-01 & $1,22^{\mathrm{B}}$ & $1,54^{\mathrm{B}}$ & $10,89^{\mathrm{A}}$ & $7,01^{\mathrm{A}}$ & $134^{\mathrm{B}}$ & $36^{\mathrm{B}}$ \\
\hline CNPGL 91 F 34-05 & $1,18^{\mathrm{B}}$ & $2,42^{\mathrm{A}}$ & $11,65^{\mathrm{A}}$ & $7,90^{\mathrm{A}}$ & $147^{\mathrm{B}}$ & $37^{\mathrm{B}}$ \\
\hline TAIWAM-146 & $0,80^{\mathrm{B}}$ & $1,60^{\mathrm{B}}$ & $11,05^{\mathrm{A}}$ & $5,60^{\mathrm{A}}$ & $113^{\mathrm{B}}$ & $30^{\mathrm{B}}$ \\
\hline CNPGL 91 F 27-01 & $0,77^{\mathrm{B}}$ & $1,56^{\mathrm{B}}$ & $11,65^{\mathrm{A}}$ & $7,88^{\mathrm{A}}$ & $189^{\mathrm{A}}$ & $44^{\mathrm{A}}$ \\
\hline CNPGL 91 F 27-05 & $0,62^{\mathrm{B}}$ & $1,05^{\mathrm{B}}$ & $10,82^{\mathrm{A}}$ & $7,27^{\mathrm{A}}$ & $249^{\mathrm{A}}$ & $46^{\mathrm{A}}$ \\
\hline Média (Mean) & 1,42 & 2,14 & 11,53 & 7,22 & 151 & 35 \\
\hline
\end{tabular}

* Médias, na coluna, seguidas pela mesma letra não diferem $(P>0,05)$ pelo teste Scott-Knott.

1 Simulando pastejo.

2 Considerando toda a parte aérea acima da altura de corte.

* Means followed by identical letters in the same column do not differ $(P>.05)$ by Scott-Knott test.

1 Simulating grazing.

2 Considering all aerial part above cutting height.

obtidas em clones com altas produções de matéria seca. Assim, os clones F 27-05 e F 27-01 mostraram tendência de serem os mais produtivos, tanto no período das chuvas, como no da seca, e também foram os que apresentaram menor relação $\mathrm{F} / \mathrm{C}$ nesses dois períodos do ano. Essa observação concorda com as de VIRGUEZ (1966), segundo o qual os clones mais produtivos de capim-elefante apresentam maior proporção de colmos, e os clones menos produtivos maior proporção de folhas. Segundo GOMIDE (1994), isso reflete diretamente na porcentagem de proteína e na digestibilidade da matéria seca.

Não foram constatadas diferenças significativas $(\mathrm{P}>0,05)$, entre os tratamentos, quanto ao teor de PB, nas duas estações do ano em estudo (Tabela 2). Na época das chuvas, observou-se tendência de o teor de PB ser mais baixo na cultivar Taiwan A-146 (testemunha) e no clone F 28-01, cujos valores foram, respectivamente, 5,60 e $5,74 \%$, e mais elevado no clone F 10-05 (9,32\% de PB). Na verdade, observouse, nessa época do ano, tendência dos clones apresentarem de maneira geral maior concentração de $\mathrm{PB}$, quando comparados com as testemunhas (cultivares Taiwan A-146 e Cameroon). A concentração média de PB na época das chuvas, considerando todos tratamentos, foi de 7,23\%. Este valor é baixo, quando comparado com outros resultados obtidos com capim-elefante, nessa mesma época do ano (BOTREL e ALVIM, 1992; BOTREL et al., 1994). Esses resultados, certamente, foram afetados pela idade avançada das plantas, na época da avaliação. Diversos autores (PEREIRA et al., 1999; JOHNSON et al., 1973) têm demonstrado que o capim-elefante apresenta queda bastante acentuada do teor de PB, após 45 dias de crescimento. Outro fato que também pode ter contribuído para a baixa concentração de PB 
foi o sistema de amostragem utilizado para a sua determinação, que consistiu de cortes manuais, considerando a planta toda, que apresentava, nessa época, alta proporção de colmos, os quais são mais pobres em $\mathrm{PB}$, quando comparados com as folhas (GOMIDE, 1994).

Durante o período da seca, o valor médio de PB foi de $10,9 \%$, considerando-se todos os tratamentos. Este valor esteve sempre acima do nível crítico de $7 \%$, estabelecido por MILFORD e MINSON (1966), abaixo do qual o consumo voluntário de forragem pelos animais pode ser comprometido. A maior concentração de $\mathrm{PB}$ observada na estação da seca certamente está relacionada com o sistema de amostragem adotado nessa época do ano - o pastejo simulado -, que consiste na colheita manual da forragem, simulando pastejo. A forragem, assim amostrada, apresenta alta proporção de folhas, que são mais ricas em $\mathrm{PB}$, quando comparadas com os colmos (GOMIDE, 1994). Além disso, o maior crescimento e desenvolvimento das plantas durante o período das águas podem ter contribuído para a menor concentração de N, devido ao efeito da diluição desse elemento na planta (WILSON, 1981).

O valor médio da concentração de PB encontrado na estação das chuvas concorda com os relatados por CARVALHO (1985), que encontrou valor médio de 9,4\% PB para o capim-elefante, considerando várias cultivares, avaliadas em diferentes tipos de solo e submetidas a diferentes formas de manejo.

Observaram-se diferenças significativas $(\mathrm{P}<0,05)$ entre tratamentos quanto ao perfilhamento aéreo e basal na época da seca (Tabela 2). Considerando-se todos os tratamentos, o número médio de perfilhos aéreos e basais, nessa época do ano, foi de 151 e 36 perfilhos $/ \mathrm{m}^{2}$, respectivamente. As testemunhas (cultivares Cameroon e Taiwan-146) situaram-se no grupo dos tratamentos que apresentaram menor $(\mathrm{P}<0,05)$ perfilhamento aéreo e basal. Aproximadamente 36 e $32 \%$ dos clones avaliados, quando comparados com as testemunhas, apresentaram maior $(\mathrm{P}<0,05)$ perfilhamento aéreo e basal, respectivamente. Estes resultados são importantes, pois maior número de perfilhos basais implica em maior número de gemas axilares para o desenvolvimento de perfilhos aéreos (JACQUES, 1994), os quais, segundo CORSI (1993), são a base de produção da pastagem durante o período de crescimento. Assim, cultivares que apresentam elevado número de perfilhos basais e aéreos poderão ser de grande importância para uso em sistema de pastejo rotativo.

\section{Conclusões}

A maioria dos clones avaliados apresentaram maior potencial forrageiro, quando comparados com as testemunhas Cameroon e Taiwan A-146.

Todos os clones avaliados apresentaram marcante estacionalidade na produção de forragem, concentrando a maior parte da produção de matéria seca no período das chuvas.

O clone F 91-27-01, lançado pela Embrapa Gado de Leite, com o nome de Pioneiro, situa-se entre os mais promissores, para quase todas as características agronômicas estudadas.

\section{Referências Bibliográficas}

ASSIS, A.G. 1982. Alimentação de vacas leiteiras. Coronel Pacheco: EMBRAPA-CNPGL, 43p. (EMBRAPA-CNPGL. Documentos, 7).

ANDRADE, I.F., GOMIDE, J.A. 1971. Curva de crescimento e valor nutritivo de capim-elefante (Pennisetum purpureum Schum.) “A-146 Taiwan”. Revista Ceres, 18(10):431-447.

BOTREL, M.A., ALVIM, M.J. 1992. Avaliações agronômicas de cultivares de capim-elefante em duas regiões fisiográficas do Estado de Minas Gerais. Pesq. Agropec. Bras., 27(6):835-839.

BOTREL, M.A., ALVIM, M.J., MARTINS, C.E. 1994. Avaliação e seleção de cultivares de capim-elefante (Pennisetum purpureum Shucum.) para pastejo. R. Soc. Bras. Zootec., 23(5):754-762.

BREMNER, J.M. 1965. Total nitrogen. In: BLACK, C.A., EVANS, D.D., WHITE, J.L. et al. (Eds.) Methods of soil analysis: chemical and microbiological properties. Madison: American Society of Agronomy. p.1148-1178.

CARVALHO, L.A. 1985. Pennisetum purpureum, SchumacherRevisão. Coronel Pacheco: EMBRAPA-CNPGL. 86p (EMBRAPA-CNPGL. Boletim de Pesquisa, 10).

CORSI, M. Manejo de capim-elefante sob pastejo. In: SIMPÓSIO SOBRE MANEJO DE PASTAGEM, 10, 1992, Piracicaba Anais... Piracicaba: FEALQ, 1993. p.143-167.

DAYRELL, M.S., NOVAES, L.P. 1992. Efeito da saliva sobre o conteúdo de magnésio, cobre, zinco e manganês em amostras de forrageiras obtidas através de animais com fístula no esôfago. Pasturas Tropicales, 14(1):41-44.

DEREZ, F., CÓSER, A.C., MARTINS, C.E. et al. Utilização do capim-elefante (Pennisetum purpureum, Schum.) para produção de leite. In: SIMPÓSIO BRASILEIRO DE FORRAGEIRAS E PASTAGENS, 1994, Campinas. Anais...Campinas: Colégio Brasileiro de Nutrição Animal, 1994. p.183-199.

ETGEN, W.M., PAUL, M.R., JAMES, E.R. 1987. Dairy cattle feeding and management. New York: John Wiley \& Sons. $638 \mathrm{p}$.

GOMIDE, J.A. 1994. Formação e utilização de capineira de capim-elefante. In: CARVALHO, M.M., ALVIM, M.J., XAVIER, D.F. (Eds.).Capim-elefante: produção e utilização. Coronel Pacheco, MG: Embrapa-CNPGL. p.81-115.

JACQUES, A.V.A. 1994. Caracteres morfo-fisiológicos e suas implicações com o manejo. In: CARVALHO, M.M., ALVIM, M.J., XAVIER, D.F. (Eds.) Capim-elefante: produção $e$ utilização. Coronel Pacheco, MG: Embrapa-CNPGL. p.31-47. 
340 Rev. bras. zootec.

JOHNSON, W.L., GUERRERO, J., PEZO, D. 1973. Cell constituents and 'in vitro' digestibility of napier grass (Pennisetum purpureum Schum.). J. Anim. Sci., 37(5):1255-1261.

LAREDO, M.A., MINSON, D.J. 1973. The voluntary intake, digestibility and retention time by sheep leaf and stem fractions of five grasses. Austr. J. Agric. Res., 24:875-888.

MILFORD, R., MINSON, D.J. Intake of tropical pastures species. In: INTERNATIONAL GRASSLAND CONGRESS 11, 1966, São Paulo, SP. Proceedings... São Paulo: Secretaria de Agricultura-Departamento da Produção Animal, 1966. p.815-822.

MATTOS, L.L. Produção de leite a pasto. In: SIMPÓSIO SOBRE TÓPICOS ESPECIAIS EM ZOOTECNIA, 1997, Juiz de Fora. Anais...Juiz de Fora: SBZ, 1997. p. 169-193.

PEDREIRA, J.V.S., MATTOS, H.B. 1981. Crescimento estacional de 25 espécies e variedades de capins. Bol. Ind. Anim., 38(1):220-231.

PEREIRA, A.V. Escolha de variedade de capim-elefante. In: SIMPÓSIO SOBRE MANEJO DE PASTAGEM, 10, 1992, Piracicaba. Anais... Piracicaba: ESALQ, 1993. p.47-62.

PEREIRA, A.V., FERREIRA, R.P., PASSOS, L.R. et al. Variação dos teores de MS, PB, FDN e FDA em capim-elefante e híbridos de capim-elefante $\mathrm{x}$ milheto, em função da idade da planta. In: REUNIÃO ANUAL DA SOCIEDADE BRASILEIRA DE ZOOTECNIA, 36, 1999, Porto Alegre. Anais...Porto Alegre: SBZ, 1999, CD-ROM.
POLI, C.H.E.C., JACQUES, A.V.A., CASTILHOS, Z.M.S. et al. 1994. Caracterização morfológica de cinco cultivares de capim-elefante. R. Soc. Bras. Zootec., 23(1):205-210.

SANTANA, J.R., PEREIRA, J.M., ARRUDA, N.G. et al. 1989. Avaliação de cultivares de capim-elefante (Pennisetum purpureum Schum.) no Sul da Bahia. R. Soc. Bras. Zootec., 18(3):273-283.

VIRGUEZ, O.G. Ensaio comparativo de 13 clones del pasto elefante (Pennisetum purpureum, Schum.). In: INTERNATIONAL GRASSLAND CONGRESS, 9, 1965, São Paulo. Proceedings... São Paulo: Secretaria de Agricultura de São Paulo - Departamento de Produção Animal, 1966, p.929-938.

WILSON, J.R. Nutritional limits to animal production from pastures. In: ENVIRONMENTAL AND NUTRITIONAL FACTORS AFFECTING HERBAGE QUALITY, 1981, $\mathrm{St}^{\mathrm{a}}$ Lucia, Qeensland. Proceedings... St ${ }^{\mathrm{a}}$ Lucia, Qeensland, 1981. p.111-131

ZUNIGA, M.P., SYKES, D.J., GOMIDE, J.A. 1967. Competição de treze gramíneas forrageiras para corte, com e sem adubação, em Viçosa. Revista Ceres, 13(77):324-343.

Recebido em: 24/06/98

Aceito em: 17/09/99 